\title{
RUTHENIUM (II)/AMINO ACID/DIPHOSPHINE COMPLEXES AS APOPTOSIS INDUCERS IN BREAST CANCER CELLS AND THEIR TOXIC EFFECTS IN ANIMAL MODELS
}

Francyelli Mello-Andrade ${ }^{1,2}$, Clever G. Cardoso³, Paulo Melo-Reis4, Cesar Grisólia ${ }^{5}$, Carlos Castro6, Carlos Menck7, Alzir A. Batista ${ }^{8}$, Elisângela Silveira-Lacerda ${ }^{1,2}$

'Laboratório de Oncologia Experimental, Instituto de Física, Universidade Federal de Goiás (UFG) - Goiânia (GO), Brazil. ²Departamento de Genética, Instituto de Ciências Biológicas, UFG - Goiânia (GO), Brazil.

${ }^{3}$ Departamento de Histologia, Embriologia e Biologia Celular, Instituto de Ciências Biológicas, UFG - Goiânia (GO), Brazil. ${ }^{4}$ Departamento de Biomedicina, Pontifícia Universidade Católica de Goiás - Goiânia (GO), Brazil.

${ }^{5}$ Departamento de Genética e Morfologia, Universidade de Brasília - Brasília (DF), Brazil.

${ }^{6}$ Departamento de Fisiologia, Instituto de Ciências Biológicas, UFG - Goiânia (GO), Brazil.

7Departamento de Microbiologia, Instituto de Ciências Biomédicas, Universidade de São Paulo - São Paulo (SP), Brazil.

${ }^{8}$ Departamento de Química, Universidade Federal de São Carlos - São Carlos (SP), Brazil.

Cytotoxicity and mechanism of action of ruthenium(II)/amino acids/diphosphine complexes were evaluated against breast cancer (MDA-MB-231 cells), as well as their toxic effects in animal models. The cell death type induced in MDA-MB-231 cells by compounds was evaluated measuring Annexin V-positive number, the activated caspases levels, and by morphological features. In order to clarify which mechanisms are responsible for led breast cancer cells to death, we evaluated whether these compounds can cause DNA damage, changes in cell cycle kinetic, mitochondrial dysfunction, and ultrastructural alterations in MDA-MB-231 cells. As toxicity assessment is a required step for preclinical study of novel metal based compounds, the acute oral toxicity was evaluated, and the genetic toxicity was determined by Micronucleus (MN) and Comet assay protocols on Swiss mice treated with these complexes. Zebrafish model was used to evaluate toxicity of $\mathrm{Ru}(\mathrm{II})$ /amino acids complexes during embryonic and larval development, more specifically, the mortality and hatching rates of zebrafish were determined. $\mathrm{Ru}(\mathrm{II})$ /amino acids complexes induced apoptosis in MDA-MB-231 cells by increase in number of Annexin V-positive cells, morphological changes, loss of mitochondrial membrane potential, and caspases-3 and 7 activation. Although these compounds have a weak interaction to DNA molecule, it was observed DNA damage, probably due to reactive oxygen species production related to mitochondrial membrane depolarization. As can be seen by ultrastructural analysis, these complexes can reduce mitochondrial amount in MDA-MB-231 cells. Thus, $\mathrm{Ru}(\mathrm{II}) / \mathrm{amino}$ acids complexes are more active for tumor cells, and their mechanism of action are related to induction cell cycle block, DNA damage, and mitochondrial dysfunction, lead to apoptosis involving p53, PARP cleavage and caspases activation. In addition, these compounds were very well tolerated orally, and it was observed lack of micronuclei formation in bone marrow cells and low DNA damage in peripherical blood cells from Swiss mice. As regard to toxicity on zebrafish embryo development, the compounds caused low embryotoxicity, being mainly observed hatching delay and mortality at high concentrations. Altogether our findings suggest that ruthenium (II)/amino acids/diphosphine complexes induce cellular and molecular responses in breast cancer cells leading to mitochondria-mediated apoptosis, and they are not harmful, presenting low systemic toxic effects. 